\title{
Dimensiones del desarrollo sustentable y el caso de México
}

\author{
Víctor L. Urquidi*
}

En la Declaración de Río de 1992 se asumió un compromiso trascendental: la adopción del objetivo del desarrollo sustentable, es decir, un desarrollo económico y social que incluya la protección ambiental y el respeto a los recursos naturales, que sea equitativo y asegure a las generaciones venideras el acceso a los recursos y a tecnologias no contaminantes para mejorar la calidad de vida a escala mundial. Hasta ahora, el balance general no ha sido positivo. Rio 5 transcurrió sin mayor resultado ni perspectiva. La conferencia de Kioto destinada a poner en marcha programas para controlar el cambio climático global no ha conseguido mucho apoyo. Ningún país ha emprendido todavia un proceso integrado de desarrollo sustentable. No es un asunto técnico, sino social y político: exige movilizar los recursos necesarios, dar prioridad al nuevo objetivo, conjugar los esfuerzos gubernamentales con los empresariales y los de la sociedad civil, crear conciencia de los umbrales peligrosos y aun irreversibles que puedan presentarse, construir una cultura de conocimiento y comunicación que contribuya al desarrollo sustentable. Éste deberá comprender el empleo de energía no contaminante; el uso proambiental del agua, los suelos y los recursos forestales; la protección de la biodiversidad; el reciclaje de desechos municipales, industriales y agricolas; la promoción de sistemas de educación y capacitación para el ambiente y la salud, y, de igual importancia, una política demográfica efectiva y de largo alcance. Ningún país podrá aislarse de esta perspectiva, y ninguna medida en particular será suficiente por si sola.

En el caso de México, pese a adelantos institucionales en materia de política ambiental a partir de 1989, el ambiente continúa deteriorándose en todos los órdenes. Los múltiples factores condicionantes de un proceso integrado de desarrollo sustentable no han contado con la prioridad, los recursos y la atención constante que se requieren en una perspectiva de largo plazo. Dada la relación particular de México con Canadá y Estados Unidos por medio del TLCAN, será urgente llevar a cabo un estudio de las perspectivas del desarrollo sustentable de los tres paises en su conjunto. Falta dar el primer paso en esa dirección.

\section{Introducción}

El propósito de esta exposición es ofrecer algunas ideas acerca de la perspectiva en que se encuentra México por lo que respecta a emprender un proceso de desarrollo sustentable. Para ello se repasa brevemente en qué deberá consistir el desarrollo sustentable y equitativo al que se comprometieron los países participantes en la Conferencia de las Naciones Unidas sobre Medio Ambiente y Desarrollo llevada a cabo en Río de Janeiro en junio de 1992. A continuación se contrasta

\footnotetext{
* Profesor emérito de El Colegio de México.
} 
dicho compromiso con lo que ha ocurrido en la práctica hasta ahora, aun teniendo en cuenta algunos avances a escala global e internacional en materia ambiental y en dirección hacia el desarrollo sustentable. Se analizan después los condicionantes de este proceso en general y la problemática de su aplicación en el caso de México, en particular a la luz de la política ambiental de los últimos años. ${ }^{1}$

\section{El compromiso del desarrollo sustentable y equitativo}

En la Cumbre de Río de Janeiro de 1992 se proclamó, mediante la Declaración de Río, firmada por los jefes de Estado o de gobierno de 178 países miembros de las Naciones Unidas, el compromiso de promover un desarrollo sustentable y equitativo.

Aunque no se ofreció una definición precisa, la lectura de esa Declaración, y del documento general de recomendaciones también aprobado, la llamada Agenda 21, lleva a la conclusión de que se trata de algo enteramente trascendental para el futuro de la especie humana: que el desarrollo futuro incorpore plenamente la protección del medio ambiente, y atienda en particular al objetivo de legar a las generaciones futuras el acceso a los recursos naturales, debidamente protegidos, que apenas una pequeña parte de la humanidad ha tenido a su alcance hasta ahora. Ello supone la debida conservación y protección de los recursos y la economía en su uso. No se pretende solamente mantener los equilibrios ecológicos del planeta. Se propone sobre todo que la actividad económica y social de la especie humana se lleve a cabo de tal manera que esos equilibrios sean posibles y permanentes.

El concepto de desarrollo sustentable tiene su origen en los años sesenta y setenta, cuando se empezó a advertir y alertar acerca del peligro de los excesos de contaminación ya percibidos. Estas advertencias se produjeron en los medios científicos, en la opinión pública y académica en general y en algunos gobiernos que ya iniciaban políticas

\footnotetext{
${ }^{1}$ Este trabajo se presentó en un taller organizado por la Comisión Económica para América Latina y el Caribe (CEPAL), subsede México, el 7 de septiembre de 1998. Las tres primeras partes de este escrito se basan en la ponencia con la que participé en el I Congreso Regional de Medio Ambiente y Desarrollo Sostenible, efectuado en Guatemala, Facultad Latinoamericana de Ciencias Sociales, Flacso, Programa Guatemala, del 17 al 21 de agosto de 1988.
} 
ambientales en relación con la atmósfera y el agua. En algún momento se recomendó el "ecodesarrollo" (Sachs, 1982). ${ }^{2}$ El Consejo del Programa de las Naciones sobre el Medio Ambiente (PNUMA) hizo suyo el concepto en sus primeros años; es más, según su segundo director general, allí se acunó el término "desarrollo sustentable" en los años setenta (Tolba, 1990: $42-43$ y 1992). Pero no fue hasta la constitución de la Comisión Mundial del Medio Ambiente y del Desarrollo (la llamada Comisión Brundtland), creada por la Asamblea General de Naciones Unidas en 1984, que rindió su informe en 1987 (Comisión Brundtland, 1987), cuando el concepto se amplió y se propuso como eje central para la Conferencia convocada en Río de Janeiro en junio de 1992. Las instancias anteriores habían visualizado el problema del medio ambiente en forma parcial, sin tener en cuenta de manera plena las múltiples interacciones sociales y económicas.

Entre 1972 y 1982 (Estocolmo+10), los índices de deterioro ambiental seguían siendo evidentes y preocupantes, no sólo en los grandes países industriales y en los principales países en vía de desarrollo, sino en todos los continentes, en las zonas polares, en los océanos y en la biósfera en general. Las soluciones no podían ser ya nacionales ni regionales, sino que además se requeriría de una visión global o planetaria. La Conferencia de 1992, convocada como resultado del Informe de la Comisión Brundtland, creó el consenso necesario para un nuevo punto de partida.

La realidad actual es que algunos recursos mundiales no renovables pueden entrar en una etapa de agotamiento o ya la han iniciado, por ejemplo, ciertos minerales y determinados hidrocarburos. Los costos de su exploración y explotación están aumentando y seguirán elevándose. Otros, como los suelos y los bosques, han sufrido daños casi irreparables, y se han contaminado de sustancias peligrosas para la salud y aun tóxicas. Ni la atmósfera, ni las aguas dulces o los océanos están a salvo. Muchos recursos naturales están amenazados de extinción, tales como importantes especies de la fauna y la flora. Existe gran incertidumbre sobre el mantenimiento de la biodiversidad. Mientras tanto, la población mundial sigue aumentando, y su actividad, organizada en distintos sistemas sociales y económicos, sigue depredando y contaminando.

${ }^{2}$ Sachs insistía en que la meta del ecodesarrollo evitaría caer en el economicismo o en el ecologismo (cf. Prólogo, por Vicente Sánchez, pp. 1-2). 


\section{El desarrollo insustentable e inequitativo}

Hoy día se cuestiona con intensidad y extensión, hasta con pasión, el resultado de lo que la humanidad, en la práctica de la relación tecnología/recursos, ha logrado en los últimos dos siglos. Pese a los grandes adelantos, la exclusión, las desigualdades y la miseria siguen predominando y en épocas recientes se han acentuado. Mediante el avance de la ciencia y la tecnología se ha extendido el dominio sobre los recursos naturales y se ha multiplicado la productividad. Sin embargo, la depredación de la naturaleza continúa, y además, se contaminan las aguas, los mares, los suelos, la atmósfera y el hábitat humano, sin considerar los efectos a futuro. Las sociedades, lejos de acercarse a un objetivo utópico y tranquilo, se aproximan a la orilla de un abismo de catástrofe, caos, violencia y descomposición social, aun de posible ingobernabilidad.

Hasta principios de los años ochenta se vivió en un ambiente de esperanza auspiciado por las Naciones Unidas y sus organismos especializados y regionales, adornado de abundante retórica oficial. Los no pocos estudios del proceso de desarrollo en las esferas universitarias y en los medios académicos y de investigación en general, concebían el desarrollo, en lo esencial, como un proceso de inversión física destinado a aumentar la capacidad productiva para proveer a la población de más bienes y servicios y de una base de estructura urbana y de transporte. Se previó también la necesidad de ampliar y mejorar los sistemas educativos, de reducir las barreras sociales, de prestar atención especial a la productividad en los sectores básicos, sobre todo en la agricultura, y de fomentar la industrialización y el empleo con apoyo en la acción del Estado.

No todo ello se ha logrado, a veces ni en mínima proporción. Ya en los años cincuenta y sesenta se comprendió, por ejemplo, en ciertos sectores de América Latina, de la India y de algunos países del Pacífico asiático y de África -con apoyo en innumerables escritos de miembros de las instituciones académicas y de funcionarios del Sistema de las Naciones Unidas- que para cumplir en un plazo relativamente corto de la historia mundial con los múltiples objetivos económicos y sociales que se planteaban, el desarrollo no se lograría de manera automática ni con resultados seguros. La sola desventaja tecnológica de los países en vía de desarrollo, la insuficiencia de sus ahorros y con frecuencia la debilidad de sus sectores de exportación y las fluctuaciones y deformaciones de los mercados a que estaban sujetos, sumado 
todo ello a sus estructuras económicas precarias, con población eminentemente rural y marginada de la modernidad, hacian prever crecientes dificultades y retrasos.

A nivel internacional, los países en desarrollo demandaban una mayor ampliación, más allá de las posibilidades del Banco Mundial y de otras instancias multilaterales, de las fuentes de financiamiento externo, para obtener éste en condiciones más favorables. Se formularon las bases de los sucesivos "decenios del desarrollo", se crearon nuevos organismos en el Sistema de las Naciones Unidas como la UNCTAD y la ONUDI, para corregir las desventajas comerciales, tecnológicas e industriales. La propia Organización para la Cooperación y el Desarrollo Económico, la OCDE, por medio del DAC, organismo interno de apoyo al desarrollo, centralizó la información sobre la cooperación financiera internacional para verificar el cumplimiento del objetivo asumido por los países desarrollados de destinar $0.7 \%$ de su PIB a ese fin (que en los últimos años se comprueba alcanza apenas de 0.2 a $0.3 \%$, lo que denota la falta de voluntad política) (OCDE, 1985).

En las visiones del desarrollo de esa época no se consideraban las consecuencias en el medio ambiente generadas por la industrialización, el transporte moderno, el incremento del comercio exterior y la aglomeración urbana, ni las de la dinámica demográfica y el cambio social. Se daba por supuesto que la actividad económica, no obstante los desechos y partículas que emitía, no ponía en riesgo el desarrollo futuro. Los planteamientos ambientales no se incluían en los planes de desarrollo y mucho menos en la teoría del desarrollo. ${ }^{3}$

Entre las advertencias hechas hacia mediados y fines de los años sesenta figuraron principalmente las de destacados científicos en Europa y Estados Unidos, cuyas observaciones y escritos comenzaron a crear conciencia en los medios de comunicación y en esferas del mundo político y de las Naciones Unidas. ${ }^{4}$ En 1972 se llevó a cabo en Estocolmo, a instancias de algunos países europeos, Estados Unidos y Japón, la Conferencia de las Naciones Unidas sobre el Medio Am-

${ }^{3}$ Como ejemplo de dos concepciones del desarrollo muy respetables pero carentes de atención al medio ambiente, he citado con frecuencia a Myrdal (1971) y a Furtado (1983). Existen, desde luego, muchas otras referencias. La evolución de estas ideas hacia el concepto de ecodesarrollo y finalmente el de desarrollo sustentable puede consultarse en un trabajo del autor, "Economía y medio ambiente", en la obra compilada por Glender y Lichtinger (1994: 47-69).

${ }^{4}$ En la obra compilada por Glender y Lichtinger, en el capítulo sobre "Economía y medio ambiente", hago referencia a esta etapa de evolución del pensamiento. 
biente Humano. Esta reunión de carácter intergubernamental contó además con un foro paralelo para la participación de las ONG y de representantes de las esferas académicas e institucionales. Las Naciones Unidas lograron apenas un éxito limitado, más bien de tipo declaratorio que otra cosa. La oposición, o por lo menos un elevado escepticismo político, provino de los países en desarrollo, del Grupo de los 77, que vieron en la política ambiental un costo insuperable y un obstáculo al propio desarrollo que, en su conceptualización estrecha y simplificada, contribuía ya al deterioro ambiental. Un delegado brasileño llegó a afirmar que se deseaba la contaminación porque significaba industrialización. Con esa posición y diversas salvaguardas nacidas de la ambigüedad de los discursos de varios jefes de gobierno de países de Asia y África, las políticas ambientales, sobre todo en los países en desarrollo, no podían encaminarse con brío y eficacia. Los países con economías de "planificación central" ni siquiera se dignaron asistir a la Conferencia. Casi como único resultado tangible se creó el PNUMA, con una aportación inicial de apenas 100 millones de dólares, para asesorar a los gobiernos e iniciar algunos programas ambientales.

También el Club de Roma había llamado la atención acerca de los peligros a largo plazo del deterioro ambiental en el nivel global en relación con la disponibilidad de recursos naturales y el incremento de la población mundial. Sus advertencias iban dirigidas en especial a los países ya industrializados, pero abarcaban asimismo a los países en vía de desarrollo. Muchas otras organizaciones privadas y académicas publicaron estudios sobre la incidencia de los fenómenos de deterioro ambiental en la economía y la sociedad, e hicieron ver la necesidad de incorporar el tema ambiental a los programas de desarrollo económico y social. Los daños posibles a la salud humana estaban ya a la vista. Las demandas sociales y políticas para la aplicación de políticas ambientales efectivas empezaron a multiplicarse.

En los años ochenta, al ocurrir el considerable aumento de los precios del petróleo crudo por acción de la OPEP, se llegó a la gran crisis del endeudamiento externo excesivo, abusivo y desordenado, de gran número de países en vía de desarrollo, lo mismo deficitarios en petróleo que dotados de capacidad de exportación de hidrocarburos. Los organismos financieros internacionales fueron incapaces de impedir ese tipo de endeudamiento directo con la banca comercial en la que se depositaban a su vez los llamados petrodólares. Esa gran crisis ha venido a reconocerse como el parteaguas del desarrollo concebido en su forma limitada original, por cuanto los paises endeuda- 
dos perdieron la poca autonomía que tenían para seguir sus propias políticas. En estas circunstancias el medio ambiente quedó arrumbado, en lugar muy bajo en la lista de prioridades, como se situó aún más la relación del desarrollo con el ambiente.

La Comisión Brundtland, en su informe Nuestro futuro común, al plantear el desarrollo sustentable, tuvo el mérito de dar un gran paso adelante, que dejaba atrás muchas de las teorías y visiones anteriores, todas ellas incompletas y carentes de atención al medio ambiente. Además de plantear el tema del desarrollo sustentable, llamó la atención sobre la necesidad de reducir el empleo de los energéticos de origen fósil -carbón, petróleo, gas- que ha caracterizado al desarrollo mundial en los últimos 200 años, y sobre todo en los recientes 50. La combustión con base en carbón y derivados del petróleo y, en menor medida, el empleo de gas natural, por sus emisiones de carbono y otros gases, explican, conforme a datos fehacientes, la creciente concentración neta de carbono en la atmósfera, no compensada por su absorción natural en los bosques y en superficies oceánicas. El llamado efecto invernadero, o sea el calentamiento gradual de la atmósfera, con su consecuencia en el nivel de los océanos, es ya tema de urgencia, como lo reconocieron la Convención Marco sobre el Cambio Climático firmada en Río de Janeiro en 1992 y la Conferencia de las Partes llevada a cabo en Kioto, en diciembre de 1997.

La Conferencia de Río, como es bien sabido, abordó asimismo los temas de la protección de la biodiversidad, la administración sustentable de los bosques y el control de la desertización. Se aprobó además una Agenda (o Programa) 21, que contiene importantes recomendaciones sobre política ambiental y desarrollo sustentable, en los niveles global, regional, nacional y local, y que considera una diversidad de instrumentos para lograr esos objetivos.

\section{Situación y tendencias actuales}

Acaba de transcurrir el momento Río+6, después de una primera evaluación Río+5 efectuada en las Naciones Unidas en junio de 1997, en una minicumbre. A la luz del informe surgido de esta cumbre (Naciones Unidas, 1997), la situación actual puede caracterizarse como de incumplimiento generalizado de las recomendaciones de la Agenda 21, y de avances muy cautelosos, o aun retrocesos, en la aplicación de las convenciones suscritas y ratificadas durante 1992-1997. Se destaca 
en el citado informe que: "Reconocemos [los países participantes] que se ha obtenido cierto número de resultados positivos, pero nos preocupa profundamente que las tendencias generales conducentes al desarrollo sustentable son peores hoy en día de lo que fueron en 1992..." (Naciones Unidas, 1997: párrafo 4). La Comisión de Desarrollo Sustentable del Consejo Económico y Social de Naciones Unidas tiene a su cargo la coordinación general y el avance en ciertos campos, pero su alcance y sus recursos son limitados. Lo único que se reconoce como un éxito considerable, que arranca desde 1991, ha sido el Protocolo de Montreal, promovido por el PNUMA, acerca de la prohibición, comercio y uso de los clorofluorocarburos (CFC) que conforme a investigaciones científicas idóneas, adelgazan la capa de ozono que protege la atmósfera de nuestro planeta del paso de dosis peligrosas de rayos ultravioleta.

El muy reciente Río+6 ha pasado sin pena ni gloria, y está todavía por verse si el Protocolo de Kioto se traducirá en políticas suficientes de reducción de emisiones de carbono en los próximos años. El asunto sigue trabado en las gruesas y a veces impenetrables esferas de los intereses económicos y políticos de varios de los principales países signatarios, no obstante numerosas ratificaciones del protocolo.

Puede afirmarse que ningún país de los que firmaron la Declaración de Río en 1992 ha emprendido una política de desarrollo sustentable y equitativo, en forma integral, en los términos previstos. Sin embargo, un número limitado de países, entre ellos casi todos los que componen la OCDE (los de Europa Occidental, Estados Unidos, Japón -pero en menor grado los de la cuenca del Mediterráneo, Australia, Corea del Sur o México-) han puesto en práctica políticas de control ambiental centradas en la reducción de las emisiones de desechos industriales y en algunos casos agropecuarios, y de desperdicios municipales, en especial por lo que hace a prevención de la contaminación atmosférica, de las aguas dulces y marinas, los suelos y los mantos freáticos. Se han construido confinamientos especiales para los desechos peligrosos y tóxicos; se han instituido reciclajes, y promovido la llamada "tecnología limpia" que supone cambios en los procesos técnicos; se han creado zonas naturales protegidas desde el punto de vista ecológico. Todo ello acompañado de políticas de comunicación, educativas y de concientización, con ayuda importante de las organizaciones no gubernamentales. Pero se ha adelantado poco, en su conjunto, en la sustitución de los energéticos más contaminantes y en la reducción de la dependencia de los sectores del transporte respecto 
al empleo de derivados del petróleo. Existe gran resistencia en muchos países que son grandes emisores de carbono -lo mismo Estados Unidos, Canadá y Australia que China- a comprometerse con reducciones efectivas de estos gases en un periodo de tiempo razonable.

Por otro lado, la necesidad de reducir la contaminación de las fuentes hídricas no ha sido abordada a nivel internacional, a la vez que se prevén condiciones de escasez futura de agua dulce en diversas regiones del planeta. Las aguas freáticas, por un lado, y los humedales, los manglares, las zonas costeras, por otro, siguen siendo envenenados y maltratados.

La falta de políticas ambientales integradas, que ocupen una posición prioritaria en los programas de los gobiernos y de la sociedad en general, se debe a que la dimensión ambiental no ha sido incorporada a la noción del desarrollo sino muy parcialmente, más bien en respuesta a demandas sociales muy concretas y localizadas.

Por una parte, la rigidez institucional y burocrática es intensa en todos los países. Por otra, prevalece en muchas partes la idea de la autorregulación. La OCDE inició sus programas ambientales en los años setenta siguiendo la pauta de algunos países industriales que habían creado sistemas de "normas y castigos", es decir, el establecimien to de normas ambientales que las empresas $u$ otros actores contaminadores (conforme al dicho de que "quien contamina paga") debían cumplir so pena de multas y hasta clausura de las empresas. En la actualidad gana terreno, poco a poco, la noción de que los sectores empresariales principales, en una perspectiva de aperturas y competitividad, sabrán en su momento -como de hecho ocurre ya con muchas empresas transnacionales y otras de gran dimensión- tomar las medidas necesarias, en el nivel de empresa, para proteger el ambiente, cumpliendo con las normas o aun excediéndose en ello.

El que una empresa lo haga no asegura, en todo caso, que lo hagan otras en su proximidad o en la misma rama de actividad. Se requieren planes o programas sectoriales o por zonas críticas. Por lo demás, el marco de competitividad entre grandes empresas deja fuera a las empresas medianas y pequeñas, que son la mayoría, aun en los paises industrializados y en particular en los países en vía de desarrollo. Estas últimas no cuentan con la información, los recursos financieros y la capacidad de gestión necesarios para hacer las inversiones que permitan cumplir las normas ambientales y evitar rebasar los umbrales peligrosos, así sea en Estados Unidos, en China o en México. Es un tema que surge cada vez más en los foros internacionales y nacionales. Mien- 
tras las grandes empresas reconocen ya que la inversión proambiental es redituable, a las demás sería necesario ofrecerles programas de apoyo y capacitación en todos los órdenes, así como incentivos -aun bajo la lógica de la apertura de mercados y de la competitividad- ya sea para prevenir el deterioro ambiental o para, a la vez, asegurar su evolución y permanencia como fuentes de empleo y de complementación de las grandes producciones industriales y de servicios.

Se afirma a veces que tal o cual empresa "hace desarrollo sustentable", pero debe precisarse que mientras no exista en el nivel de nación un conjunto de políticas económicas y sociales, incluso sobre la administración de recursos naturales, que conduzca al desarrollo sustentable, las empresas sólo estarán cumpliendo con normas específicas o con orientaciones particulares de la política ambiental, pero sin tener en cuenta los objetivos nacionales e internacionales de conjunto. Es evidente que las empresas, sean privadas o estatales, en sus compras de insumos, en su producción y distribución o en su participación en políticas nacionales, no siempre se guían por la lógica del desarrollo sustentable.

En el panorama internacional, por otra parte, si el desarrollo sustentable, definido en su sentido más general previsto en la Conferencia de Río, no ha sido emprendido plenamente por ningún país, cabría preguntar si las políticas ambientales nacionales, regionales e internacionales, promovidas por diversos organismos internacionales y por los gobiernos nacionales, son suficientes para encaminar a las sociedades hacia el desarrollo sustentable. La respuesta a esta pregunta está enmarcada en la incertidumbre acerca de lo que hoy se entiende por desarrollo, sea sustentable o no; es decir, se acentúa en las distintas instancias la idea del simple crecimiento, registrada en lo general por algún índice del cambio en el valor de los grandes agregados -el PIB, por ejemplo-, sin consideración de los daños simultáneos que el crecimiento impone a los recursos naturales, a la salud humana y al hábitat. Se ha impuesto la necesidad, que se extiende con gran lentitud, de elaborar, además de las cuentas nacionales -la medición de los agregados económicos-, las cuentas ambientales -el cálculo del costo de la pérdida de activos naturales, sean materiales o humanos. Lo que en algunos casos pueda parecer un incremento del PIB, o por lo menos de la componente inversión productiva, puede en realidad quedar contrarrestado por una pérdida de capital real en la naturaleza, en la calidad de vida o en el sector humano, que puede traducirse en menor ingreso futuro. Mientras no se integren las cuentas ambien- 
tales, y se hagan los análisis correspondientes en los niveles concretos y no solamente en grandes agregaciones, poco se podrá suponer respecto a avances hacia un proceso de desarrollo sustentable.

En general, la idea del desarrollo sustentable no ha penetrado en la sociedad ni en los gobiernos al grado de que sea una base firme de formulación de políticas de desarrollo, donde éstas lleguen a considerarse necesarias. Suelen prevalecer los objetivos a corto plazo. En particular, no se han identificado de maneras adecuadas las rigideces estructurales, las resistencias de todo orden a que se enfrenta el cambio, por lo menos en los sectores críticos. La mayoría de las resistencias son difíciles de cambiar con rapidez. Existe un gran vacío entre las formulaciones teóricas del desarrollo sustentable y la práctica política, económica y social. Prevalece, además, una excesiva conformidad con la idea -también teórica- de que en el marco de mercados libres y competitivos, nacionales o internacionales, se generan las condiciones que permitirán abordar, por simple interés propio de los grandes sectores empresariales, las políticas ambientales y otras necesarias -por ejemplo, respecto a energéticos y agua-que detendrían el deterioro ambiental.

No se ha avanzado en construir los cimientos que, con el concurso de sociedades civiles participativas, conduzcan con el tiempo a aceptar los procesos de desarrollo sustentable que a largo plazo pudieran evitar las grandes amenazas sociales y ambientales que se ciernen sobre la humanidad, y que permitirían asegurar a las generaciones futuras, en condiciones equitativas, el acceso a niveles de vida y bienestar aceptables.

Una de las condiciones implícitas -y aun explícitas en los documentos de Río de Janeiro- es que no basta que un país, una sociedad, se propongan por sí solos encaminarse al desarrollo sustentable. Se necesita que la idea sea aceptada y cumplida por todos los principales países que en la esfera económica ojerzan gran influencia en el sistema mundial: sean industriales, agrícolas o petroleros. Se requiere asimismo que la cooperación internacional, hoy tan menguada, se oriente hacia esa finalidad y reconozca, además, las desigualdades preexistentes y la capacidad diferencial para salir del atraso, para llevar a la práctica políticas ambientales efectivas y para asumir las responsabilidades del desarrollo sustentable en todos los terrenos.

Por lo mismo, dentro de cada nación será indispensable que el desarrollo sustentable sea un objetivo colectivo, no limitado a algunas regiones críticas o a determinados sectores. De nada sirve que una región 
de un país aborde el desarrollo sustentable mientras otra vecina o conectada con ella no lo haga. El enfoque deberá ser integral y sistémico.

En tanto prevalezcan los intereses más inmediatos de los principales países industriales del mundo, apoyados en las instancias políticas respectivas que responden casi siempre a intereses privados, y mientras las naciones excluidas por ahora de ejercer influencia en las demás no puedan llegar a tener mayor capacidad de acción, o se limiten a formular posiciones defensivas, el desarrollo sustentable puede no pasar de ser una elegante quimera.

Mas ¿qué otro camino le queda a la humanidad? La globalización se ha intensificado en los decenios recientes. Comprende en lo principal al comercio y las inversiones y alcanza en particular a las comunicaciones, la transmisión del conocimiento y de la información de todo tipo. Es un proceso que dificilmente se detendrá. En la globalización, por el dominio que ejerce el paradigma del mercado abierto y competitivo, tenderán a beneficiarse en mayor medida los países con economías más fuertes y con mayor dominio de la innovación tecnológica, o los agrupamientos de países que compartan objetivos comunes a futuro en estas materias. Muchos países, si no la mayoría, no están todavía en condiciones de aprovechar las posibles ventajas de la globalización, ni siquiera de evitar sus efectos desfavorables. Para cualquier sociedad que haya llegado tarde a esta gran coyuntura histórica, el esfuerzo de definición de objetivos a largo plazo y de construcción de capacidad de lograrlos vía la educación, las estrategias económicas y sociales y la creación de condiciones de convivencia política democrática, tendrá que ser mucho mayor que el emprendido con anterioridad. Si en ese esfuerzo se incorpora la compleja noción del desarrollo sustentable, con sus posibles beneficios de equidad social, se podrá asegurar un resultado más valioso para las poblaciones futuras que si se sigue haciendo más de lo mismo o apenas atendiendo las exigencias de corto plazo. ${ }^{5}$

La globalización y el desarrollo sustentable tienden cada día más a constituir un marco en el que tendrá que considerarse la interac-

\footnotetext{
${ }^{5}$ Para el caso de México, una sociedad que se encuentra atrapada entre las tendencias de la globalización y la resistencia al cambio, se ofrece una base para el debate en un informe de la Sección Mexicana del Club de Roma, coordinado por el autor (Urquidi, 1996a). No se tiene hasta ahora noticia de ningún otro estudio semejante hecho en un país latinoamericano.
} 
ción de todos los elementos, en los niveles mundial y regional. Igualmente será necesario hacerlo en la esfera nacional de cada país, y en la interrelación de unos países con otros situados en su zona de influencia o de agrupamiento subregional, como por ejemplo, en el caso del Mercosur, o el de Centroamérica.

En suma, el camino del desarrollo sustentable está todavía por andarse. Ningún país lo ha emprendido aún. El deterioro ambiental, económico y social, que se registra casi sin excepción en todos los países, hace ver la necesidad de dar mucho mayor impulso a los compromisos de Río de Janeiro. Las políticas ambientales no son sino una parte, ciertamente importante, al lado de otras en las esferas política, económica y social, de un proceso integrado de desarrollo sustentable. No se trata de un problema técnico-ecológico solamente, sino que es al mismo tiempo social y político. Exige movilizar recursos, dar prioridad al nuevo y complejo objetivo, conjugar los esfuerzos societales, los gubernamentales con los de los sectores empresariales y de la sociedad civil. Habrá de crearse mayor conciencia de los umbrales peligrosos que se aproximan, de medir los riesgos y tomar las acciones adecuadas, de evitar la irreversibilidad de algunos procesos de contaminación ambiental, de construir una cultura institucional de conocimiento y comunicación que contribuya al desarrollo sustentable.

Toda medida aislada, por útil que fuere, será por sí sola insuficiente. Se trata de una problemática compleja que requiere adoptar estrategias coordinadas a largo plazo y supone el involucramiento de la sociedad como un todo. Ningún país, ninguna región, podrán aislarse de esta transición hacia el futuro más lejano. La cooperación internacional multilateral deberá ser un elemento indispensable, llevada a cabo de común acuerdo y tendiente a favorecer la acción de las sociedades menos protegidas o capacitadas para la nueva era.

\section{La perspectiva del desarrollo sustentable en México}

Dejando para la historia la admirable labor intelectual y práctica de algunos conservacionistas mexicanos en los primeros decenios del presente siglo, no se prestó atención a una política ambiental propiamente dicha sino en relación con la Conferencia de Estocolmo de 1972, en la que México estuvo representado, previa aprobación de un principio de legislación. Se situó la política ambiental como problema de la salud, en la secretaría respectiva, sin mayor consecuencia. 
En 1988 se hizo aprobar en el Congreso la Ley de Equilibrio Ecológico y de Protección al Ambiente, previa localización de los asuntos ambientales en una Subsecretaría de Ecología (no se le llamó de Medio Ambiente), en la Secretaría de Desarrollo Urbano y Ecología. A los pocos años, en el marco de dicha secretaría de Estado, se creó el Instituto Nacional de Ecología y se entró de lleno en el sistema de normas y castigos para administrar la política ambiental, aunque fuera en forma parcial. El primer diagnóstico ambiental nacional se publicó en 1990 (Sedue, 1990); si bien incompleto, reconocía la gravedad del deterioro ambiental, pero no ofrecía un programa concreto. Cabe observar que se aproximaban los preparativos para la Cumbre de Río, de manera que el INE compiló un estudio de situación ambiental en el cual se incluyó mucha más información que se presentaría en la Conferencia, bajo los auspicios de la Secretaría de Desarrollo Social (Sedesol, 1992). Esta misma secretaría daría a conocer un informe bastante más completo después de la Cumbre (Sedesol, 1994) en el que se profundizó en gran parte de la información y se dejó a la vista un cuadro bastante preocupante de deterioro ambiental en cuanto a emisión de desechos, contaminación del agua, falta de confinamientos y otros indicadores. En diciembre de 1994 se creó la Secretaría de Medio Ambiente, Recursos Naturales y Pesca (Semarnap), incorporando en ella el INE, la Comisión Nacional del Agua, el Instituto de Pesca y otros organismos existentes. Apenas en 1996 se dio a conocer el llamado Programa de Medio Ambiente 1995-2000 (Poder Ejecutivo Federal, Semarnap, 1996), en el cual se presenta un diagnóstico "funcional para una estrategia de desarrollo sustentable" que identifica procesos que "plantean grandes líneas o dimensiones", por cierto bastante discutible. ${ }^{6}$ No se conoce ningún estudio que haya incidido en los propósitos de dicho programa, que incluía seis "líneas argumentativas para un diagnóstico comprensivo". Por otro lado, no se ha publicado sino hasta 1999 el estudio bienal de situación ambiental en México correspondiente a 1995-1996.

Aparte de las consideraciones generales que se han hecho, la política ambiental en los últimos años se ha enfocado en medida importante a la protección de ciertos recursos naturales en las llamadas zona protegidas, al conocimiento de la biodiversidad, a una mejor aplicación de las normas ambientales para la industria, a aspectos concretos como la contaminación atmosférica en la Zona Metropoli-

${ }^{6}$ En su momento hice un análisis de este documento, que podrá encontrarse en Urquidi (1996b). 
tana de la Ciudad de México, a temas específicos en la zona de la frontera norte, a la construcción institucional, la formación de recursos humanos y la obtención de apoyos financieros para los programas. En 1996, después de un largo periodo de consultas, incluso con sectores no gubernamentales, se reformó la ley de 1988, adicionándosele facultades no antes especificadas para las autoridades ambientales, bases para una mejor descentralización en su ejecución, y un pequeño capítulo sobre instrumentos económicos para el cumplimiento de las normas ambientales. También se ha promovido mayor calidad y extensión en las investigaciones ambientales.

No puede negarse que se ha intensificado la atención del gobierno federal y de muchos de los gobiernos estatales, y aun de algunos municipales, a la problemática ambiental. Sin embargo, puede afirmarse al mismo tiempo que la política ambiental en México adolece de falta de coordinación entre secretarías de Estado y entidades paraestatales, y de capacidad de las autoridades locales para asumir sus responsabilidades. No siendo suficientes los recursos destinados a la política ambiental, tampoco se ha asumido para la misma una prioridad nacional adecuada. En la carrera contra el tiempo, los avances institucionales y de diagnóstico pierden terreno ante la progresión del deterioro en todos los ámbitos. En particular se ha desatendido el problema de la emisión de desechos peligrosos por la industria y otras actividades económicas, aun en lo que hace a recolección de basura, y se está produciendo un grave retraso en la construcción de confinamientos, en la instalación de servicios de reciclaje de desechos y de agua. En materia de energía se han iniciado algunas acciones para sustituir los combustibles más contaminantes, pero el volumen de emisiones netas de carbono hacia la atmósfera, precursoras del efecto invernadero en escala global, continúa aumentando. México no adoptó una posición claramente definida en relación con el Protocolo de Kioto de 1997. En cambio, fue de los primeros países que ratificaron el Protocolo de Montreal sobre la producción y comercio de clorofluorocarburos (CFC), aunque hay indicios de que es también uno de los países en que se manifiesta contrabando de ellos. México es también uno de los pocos países que siguen produciendo DDT y utilizándolo. La economía energética no ha sido sometida a acciones prioritarias, como tampoco se ha reducido el desperdicio de agua dulce ni se ha reducido su contaminación.

El panorama que ofrece México en materia ambiental indica a todas luces una enorme distancia entre lo que pudiera ser una política 
ambiental efectiva y la realidad. Para tomar un ejemplo importante, si bien es cierto que muchas de las grandes empresas industriales, sobre todo en los sectores de exportación, han emprendido importantes programas técnicos y promocionales sobre mejoras ambientales concretas, lo alcanzado por las empresas medianas y pequeñas ha sido bastante limitado debido en gran medida a que no existen programas de incentivos económicos y de capacitación destinados a lograrlo, que el gobierno conjuntamente con el sector empresarial pudieran diseñar y llevar a la práctica. Existen estudios que demuestran que la pequeña industria no practica un "comportamiento ambiental" adecuado, ni tiene acceso a la información necesaria ni menos aún a los recursos financieros que pudieran incentivarla. Por otro lado, se dan también ejemplos notables, en pequeña escala, de avances en la capacidad de gestión ambiental, pero sin mayor consecuencia general.

En el campo de la información y la concientización ambientales, y pese a lo que divulgan los diversos medios de comunicación, falta mejor definición de mecanismos para que la información lleve a resultados prácticos. En el terreno educativo es poco lo que se ha avanzado, como ocurre asimismo en el área de la capacitación.

De lo afirmado hasta aquí sobre las dificultades para encaminar a los países, las regiones, la comunidad global, hacia el desarrollo sustentable y equitativo, puede deducirse que aún menos se ha logrado una orientación hacia el desarrollo sustentable en México, por más que la frase "desarrollo sustentable" sea empleada en forma bastante extendida aunque imprecisa. Las circunstancias por las que atraviesa la sociedad mexicana desde hace varios años no han sido propicias para el desarrollo sustentable porque están ausentes tres grandes elementos: 1) la falta de objetivos económicos y sociales en plazos mediano y largo dentro de los cuales pueda encuadrar el desarrollo sustentable; 2) la incapacidad de la sociedad mexicana para acometer programas y acciones que eliminen las causas de la desigualdad en las condiciones sociales y corrijan los efectos más graves de la marginalidad, por un lado, y de la concentración económica, por otro, y 3) la dificultad para generar consensos en materias que afecten intereses y resistencias diversos sin los cuales el propósito del desarrollo sustentable no puede alcanzar la prioridad necesaria ni en las esferas de gobierno ni en las de la sociedad civil.

Sería erróneo y dañino suponer que con un poco de mejoría en la política ambiental concreta, una mejor divulgación de la problemática ambiental, la introducción de unos cuantos cursos de capacitación, o 
una aplicación más rigurosa de las normas existentes, se desbrozaría el camino para avanzar hacia un desarrollo sustentable y equitativo. Si todo ello no va acompañado de campañas sociales y políticas comprensivas en las que el desarrollo sustentable alcance a ser una divisa real y no una frase de fácil empleo, puede llegarse a situaciones irreversibles de deterioro ambiental y social; se llegará a umbrales peligrosos de deterioro interrelacionados cuya corrección podrá tener un gran costo económico, sin tiempo para prevenirlos con conjuntos de programas y acciones interrelacionados que den nuevas dimensiones al desarrollo y al bienestar, tanto en nivel nacional como en escalas regionales.

En México, dicho llanamente, no se ha dado el primer paso para emprender un proceso de desarrollo sustentable y equitativo. El que en otros países, en lo general, tampoco se haya avanzado, no obstante algunos casos de buenas políticas ambientales en determinadas áreas, no debe, en todo caso, llevar a la conclusión de que pueda aplazarse una estrategia de desarrollo sustentable en México, no porque existan compromisos morales como los de la Conferencia de Río de Janeiro de 1992 u otros nacidos de la convivencia internacional, sino porque convendrá a la población futura de México y a la sociedad mexicana avizorar un desarrollo sustentable. Los requisitos son muchos y habrá que icflexionar muy específicamente en la complejidad de la problemática y las posibilidades do la sustentabilidad a largo plazo.

La dimensión nacional tampoco podrá definirse en forma aislada 1. lo que ocurra a nivel mundial, en el contexto de las tendencias de la globalización. Sin ir demasiarlo lejos, podría partirse del hecho de que páa México, en el terreno del comercio, las inversiones y la transformación tecnológica, asi : nmo en el financiero, la globalización se define principalmente en la awociación con Estados Unidos y Canarlá por medio del Tratado de Libre Comercio de América del Norte y los convenios paralelos. Si bien el TICAN no llega al extremo de la Unión Europea, en que lo ambiental se ha vuelto parte del proceso de integración regional total y en muchos aspectos preeminente, el Convenio de Cooperación Ambiental (CCA) entre los tres países signatarios representa la obligación de asumir el objetivo del desarrollo sustentable, aunque sólo aparezca en el preámbulo. Más allá de esta buena intención, estaría la conveniencia nacional de cada país, y en este caso de México, por las razones apuntadas, de hacer efectiva la aspiración del desarrollo sustentable.

Sin embargo, transcurridos casi cinco años desde la puesta en vigor del TI.CAN, están todavía por precisarse los efectos del incremento del 
comercio sobre el medio ambiente, y a la inversa, los efectos de los requisitos ambientales sobre el comercio y la inversión. El CCA ha promovido estudios sobre estas materias, pero no han recibido atención prioritaria. No hay más que considerar lo que ocurre en la zona de la frontera entre Estados Unidos y México así como en ciertos aspectos de las relaciones en la frontera entre Canadá y Estados Unidos. Además, ninguno de estos dos países en particular ha avanzado en forma propositiva y eficaz hacia la dimensión compleja y múltiple del desarrollo sustentable, a pesar de la mayor concientización de la sociedad civil en ambos países, de la que se tienen muestras cotidianas. Privan los grandes intereses industriales y comerciales sobre los a su vez grandes problemas ambientales, por ejemplo, en materia de energía basada en hidrocarburos, como fue evidente en las negociaciones previas al Protocolo de Kioto sobre cambio climático y en el contenido de los compromisos asumidos en este convenio multilateral a partir de diciembre de 1997.

En la relación comercial México-Estados Unidos no se ha pasado de hacer estudios generales, por una parte, y de iniciarse un proceso creciente de denuncias sobre acciones empresariales que dañan el ambiente. Más que la protección del ambiente parece prevalecer el interés de proteger intereses económicos, al menos en Estados Unidos, y en menor escala en Canadá, que se consideran afectados o amenazados por el comercio proveniente de un país, México, con salarios más bajos y con menor capacidad para aplicar sus políticas ambientales. Mientras no se salga de las generalidades en que se traten el comercio y el ambiente en grandes agregados sin entrar en el análisis de los principales renglones del comercio recíproco, tanto en sus productos acabados como en las cadenas de producción y distribución, tanto upstream como dounstream, con el fin de detectar los puntos precisos en que se transgreden normas ambientales, teniendo en cuenta los insumos importados, los servicios de transporte, los empaques y la distribución, no se habrá avanzado en el conocimiento de la relación comercio/ambiente. ${ }^{7}$ Un análisis de este tipo requeriría por lo menos escoger unos veinte renglones importantes del intercambio de mercancías y sus servicios conexos, no para limitarse a denunciar los daños sino para proponer soluciones que puedan llevarse a la práctica en plazos razonables, con la cooperación que puedan brindar el CCA y otros medios o mecanismos. Algunos aspectos de la apertura generada por el

\footnotetext{
${ }^{7}$ Me remito a un trabajo sobre este tema publicado por El Colegio de la Frontera Norte (Urquidi, 1997).
} 
TLCAN merecerían un examen pormenorizado de las consecuencias sociales del nuevo comercio, por ejemplo, en materia de importaciones de maíz norteamericano a México. ${ }^{8}$

Si en asuntos ambientales el avance ha sido lento, es evidente que en cuestión de desarrollo sustentable lo será aún más, ya que ni siquiera existe un estudio comparable de carácter general sobre las políticas y perspectivas del desarrollo sustentable de Canadá, Estados Unidos y México. Llevarlo a cabo sería un peldaño necesario para abrir en todas sus dimensiones la interrelación sustentable del comercio, las inversiones y la innovación tecnológica entre los tres signatarios del TLCAN. Independientemente de que México efectuara su propio estudio de prospectiva de la sustentabilidad, no debiera sustraerse a las posibilidades de que se hiciera en un marco de cooperación, porque a la larga será de interés y utilidad para la interpretación a futuro de la sociedad mexicana en el marco de la globalización.

\section{Bibliografía}

Comisión Brundtland (1987), Nuestro futuro común, Informe de la Comisión Mundial del Medio Ambiente y del Desarrollo (Comisión Brundtland), Madrid, Alianza Editorial.

Furtado, Celso (1983), Breve introducción al desarrollo: un enfoque interdisciplinario, México, Fondo de Cultura Económica.

Glender, Alberto y Víctor Lichtinger (1994), La diplomacia ambiental, México, Fondo de Cultura Económica/Secretaría de Relaciones Exteriores.

Myrdal, Gunnar (1971), Asian Drama: An Inquiry into the Poverty of Nations, Nueva York, Vintage Books.

Naciones Unidas (1997), "Programme for the Further Implementation of Agenda 21", Special Session of the General Assembly, 23-27 de junio, Departamento de Coordinación de Políticas y de Desarrollo Sustentable, Naciones Unidas (hay versión en español) (mimeo.).

OCDE (1985), Twenty-five Years of Development Co-Operation: A Review, Paris, OCDE [e informes anuales sucesivos].

Poder Ejecutivo Federal y Semarnap (1996), Programa de Medio Ambiente 19952000 , México.

Sachs, Ignacy (1982), Ecodesarrollo: desarrollo sin destrucción, México, El Colegio de México.

${ }^{8}$ No se ha dado a conocer aún al público un trabajo emprendido por la ccA sobre esta materia. 
Sedesol (1992), México: Informe de la situación general en materia de equilibrio ecológico y protección al ambiente, 1991-1992, México, Instituto Nacional de Ecología

(1994), México: Informe de la situación general en materia de equilibrio ecológico y protección al ambiente, 1993-1994, México, Instituto Nacional de Ecología.

Sedue (1990), Programa Nacional para la Protección Ambiental 1990-1994, México. Tolba, Mostafa K. (1990), Reseña del PNUMA, Naciones Unidas.

(1992), "To Regain our Lost Days", discurso pronunciado en la Universidad de Guadalajara, Jalisco, 27 de noviembre (mimeo.).

Urquidi, Víctor L. (coord.) (1996a), México en la globalización: condiciones y requisitos de un desarrollo sustentable y equitativo, Informe de la Sección Mexicana del Club de Roma, México, Fondo de Cultura Económica.

(1996b), El medio ambiente en México. Diagnóstico, programas y perspectizas, Culiacán, El Colegio de Sinaloa (Cuadernos, 21).

- (1997), "Los problemas del medio ambiente en las relaciones MéxicoEstados Unidos", en Eliseo Mendoza Berrueto (coord.), Sociedad y politica: México y Estados Unidos, una visión recíproca, Tijuana, El Colegio de la Frontera Norte, pp. 15-41 (reproducido también en Foro Internacional, vol. 37, núm. 2, pp. 181-291). 